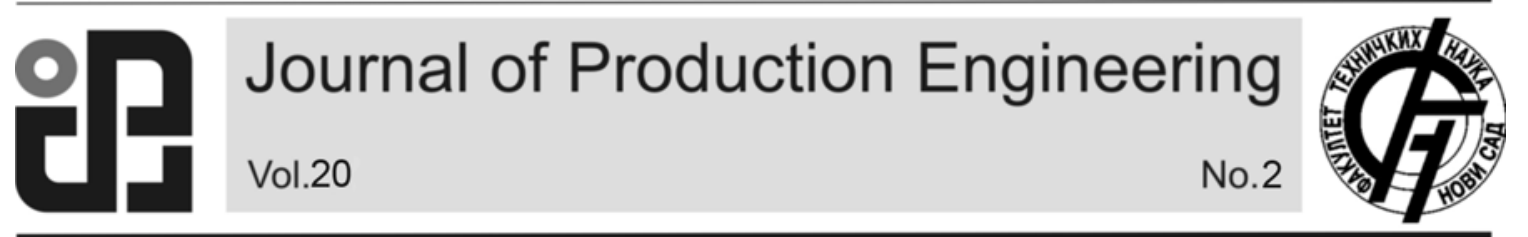

JPE (2017) Vol.20 (2)

Madić, M., Radovanović, M., Kovačević, M.

Original Scientific Paper

\title{
AN OPTIMIZATION APPROACH FOR PRODUCTION TIME MINIMIZATION IN LONGITUDINAL TURNING
}

Received: 04 September 2017 / Accepted: 17 November 2017

\begin{abstract}
One of the ways for increasing turning efficiency and economics is formulation and solving optimization problems through the use of mathematical models and optimization methods and algorithms. Ability to deal with complex and multi-dimensional optimization problems resulted in the use of a number of different optimization methods and algorithms for solving turning optimization problems, formulated either as single or multi-objective optimization problems with or without constraints. This study promotes the use of conceptually simple and parameter free optimization approach based on the use of exhaustive iterative search. To this aim optimization problem of single-pass turning process was considered. The proposed optimization approach was employed for determining optimal turning conditions, in terms of cutting speed, feed rate and depth of cut, so as to minimize total production time while considering four non-linear constraints. The obtained optimization solutions were compared with those obtained by the previous researchers using different meta-heuristic algorithms including genetic algorithms, simulated annealing, particle swarm optimization, differential evolution etc.
\end{abstract}

Key words: turning, optimization with non-linear constraints, production time

Jedan optimizacioni pristup za minimizaciju vremena obrade kod uzdužnog struganja. Jedan od načina za povećanje efikasnosti obrade struganjem je formulisanje $i$ rešavanje optimizacionog problema korišćenjem matematičkih modela, kao i algoritama i metoda optimizacije. Proteklih godina razvijen je veliki broj različitih algoritama i metoda za rešavanje brojnih problema optimizacije, uključujući jednokriterijumske $i$ višekriterujske sa ili bez ograničenja. Ovaj rad promoviše primenu konceptualno jednostavnog, bezparametarskog optimizacionog pristupa zasnovanom na primeni algoritma iterativnog pretraživanja. U tu svrhu razmatran je problem optimizacije uzdužnog struganja za jedan prolaz alata. Cilj je bio da se odrede optimalne vrednosti brzine rezanja, dubine rezanja i koraka kako bi se minimizovalo vreme obrade, uzimajući u obzir i četiri nelinearne funkcije ograničenja. Dobijeni optimizacioni rezultati su upoređeni sa rezultatima autora koji su primenjivali različite metaheurističke algoritme kao što su genetski algoritam, simulirano kaljenje, optimizacija rojem čestica $i$ dr.

Ključne reči: struganje, optimizacija sa nelinearnim ograničenjima, vreme obrade

\section{INTRODUCTION}

As in other machining process operations, optimization of turning parameters is of great importance. Since adequate turning condition setting can directly minimize production cost and maximize productivity, while satisfying quality and process requirements at the same time, optimization of turning process represents an active field of research. In a given turning operation, optimization aims at selecting the most desirable set of turning parameter values for cutting speed, feed rate and depth of cut so as to obtain maximum productivity (or minimal production time), minimal production cost (or maximal profit) or achieve a certain balance between selected objectives. In some broader optimization problem formulation necessity to include certain constraints, such as allowable machine tool power, cutting tool life, required surface roughness of the workpiece, allowable cutting force, temperature etc., arises. A central place in the optimization process formulation represent mathematical models devoted to establishing relationships between turning parameters (independent variables) and objectives (turning performances).

Upon development of these models, either analytically, empirically or combination of both, these mathematical models are used for formulation of different types of optimization problems including single-objective as well as multi-objective with and without constraints. So far, for solving complex turning optimization problems with several non-linear constraints, a wide spectrum of optimization methods and algorithms has been proposed. Early work in the field of turning process optimization was based on the use of analytical approaches, differential calculus and application of Lagrange multipliers method [1]. Later on, a number of researchers focused on the application of linear, non-linear, geometric, dynamic and goal programming methods [2]. Optimization of parameters in turning process with the use of Nelder Mead simplex search method was discussed by [3]. Mesquita et al. [4] applied Hooke-Jones pattern search method for optimization of multi-pass turning process. Recently, the new trend for solving turning optimization problems considers the use of meta-heuristic algorithms. Saravanan et al. [5] applied genetic algorithm (GA) and simulated annealing (SA) for optimization of turning parameters so as to minimize production time. In a related research Saravanan et al. [6] applied tabu search (TS), memetic algorithm (MA), 
ant colony optimization (ACO) and particle swarm optimization (PSO) to minimize production cost. Optimization of multi-pass turning operations using ACO was also attempted by Vijayakumar et al. [7]. The turning parameters were determined by minimizing the unit production cost, subject to various practical machining constraints. Ameur and Assas [8] applied modified PSO for optimization of cutting speed, feed rate and depth of cut so as to achieve desirable compromise between the extent of material removal rate and tool wear. In order to achieve minimum production time in single-pass turning process, Bharathi Raja et al. [9] applied firefly algorithm (FA). The optimization framework was based on the optimization model proposed by Agapiuou [3]. The same algorithm was later applied by Belloufi et al. [10] for determination of optimized conditions in a multipass turning process. The optimization problem was formulated so as to achieve minimization of production cost under a set of machining constraints. Chauhan et al. [11] applied LXPM, a real coded GA which uses Laplace probability distribution in the crossover phase, and differential evolution (DE) for determination of optimal machining conditions in $\mathrm{CNC}$ turning process. Chauhan et al. [12] proposed the use of totally disturbed PSO (TDPSO) for obtaining optimal turning conditions during multi-pass turning operations subject to various constraints. Mellal and Wiliams [13] applied cuckoo search algorithm (CSA) for minimization of the unit production cost of multi-pass turning operations. Optimization of depth of cut in multi-pass turning using metaheuristic algorithms such as GA, SA and ACO was performed by Satishkumar et al. [14]. The optimization framework was based on the optimization mathematical model proposed by Shin and Joo [15]. Srinivas et al. [16] applied PSO for optimization of multi-pass turning process so to obtain the set of cutting parameters that minimize unit production cost subject to practical constraints. In the optimization study, the mathematical model proposed by Chen and Tsai [17] was selected, which involves multiple rough cuts and a single finish cut. Optimization of multi-pass turning operations using hybrid teaching-learningbased optimization (TLBO) algorithm was considered by Yildiz [18]. The goal was to determine turning parameters considering minimum production cost under a set of machining constraints which were presented and adopted by Shin and Joo [15] and Chen and Tsai [17]. Recently, an improved flower pollination algorithm (FPA) for solving multi-pass turning optimization problem was proposed by $\mathrm{Xu}$ et al. [19]. Optimization model proposed by Shin and Joo [15], which takes the unit production cost as the minimizing objective and involves some practical constraints, was used to examine the efficiency of the FPA.

Although traditional optimization methods, based on the use of gradients, can produce acceptable solution, they cannot deal well with integer/discrete independent variables. On the other hand, ability of metaheuristic algorithms to deal with discontinuous, non-differentiable, and multi-dimensional turning mathematical models made them become popular for solving turning optimization problems. However, they posses certain drawbacks, and as primary, inability to prove the optimality of the determined solution, can be listed. In that sense for solving turning optimization problems with nonlinear constraints a more robust approach may be more justified. The motivation of this study is to promote the use of conceptually simpler, and, arguably, easier for practitioners optimization approach based on the use of exhaustive iterative search. In such way optimality of the determined optimization solution would be guaranteed.

\section{TURNING OPTIMIZATION PROBLEM FORMULATION}

In the present study, optimization model proposed by Agapiuou [3] was adopted and analyzed. Therefore, the production time $\left(T_{u}\right)$, which is the sum of machining time $\left(t_{m}\right)$, tool quick return time $\left(t_{R}\right)$, tool changing time $\left(t_{c s}\right)$ and workpiece handling time $\left(t_{h}\right)$, was considered as objective function:

$$
T_{u}=t_{m}+t_{c s} \frac{t_{m}}{T}+t_{R}+t_{h}
$$

The machining time per pass is given as:

$$
t_{m}=\frac{\pi \cdot D \cdot L}{1000 \cdot v \cdot f}
$$

where $D$ is workpiece diameter, $L$ is length of the workpiece, $v$ is the cutting speed and $f$ is the feed rate.

Taylor's tool life equation, given by the following power model:

$$
v \cdot f^{a_{1}} \cdot a_{p}^{a_{2}} \cdot T^{a_{3}}=K
$$

where $a_{p}$ is the depth of cut, and $a_{1}, a_{2}, a_{3}$ and $K$ are empirical constants, can be used for estimation of tool life $(T)$ in Equation 1.

The main turning parameters are ussualy specified by machinist considering past experience and tool maker recommendations. In that sense, maximum and minimum permissible values for these parameters are given as:

$$
\begin{aligned}
& v_{\min } \leq v \leq v_{\max } \\
& f_{\min } \leq f \leq f_{\max } \\
& a_{p_{\min }} \leq a_{p} \leq a_{p_{\max }}
\end{aligned}
$$

During actual turning operation, the cutting power should not exceed the maximal allowable power $\left(P_{\max }\right)$ provided by the machine tool. Thus the constraint for cutting power may be given using the following empirical relationship in the form:

$$
0.0373 \cdot v^{0.91} \cdot f^{0.78} \cdot a_{p}^{0.75} \leq P_{\max }(5)
$$

The tool workpiece interface temperature constraint can be given in the following form: 


$$
74.96 \cdot v^{0.4} \cdot f^{0.2} \cdot a_{p}^{0.105} \leq \theta_{\max }
$$

where $\theta_{\max }$ is the maximal temperature of tool workpiece interface.

Due to resistance of workpiece material, the cutting force occurs in turning operations. Cutting force in turning is influenced in varying amounts of different factors including cutting parameters, tool related parameters, properties of work pieced material and environment parameters. In terms of main parameters cutting force constraint can be given as:

$$
844 \cdot v^{-0.1013} \cdot f^{0.725} \cdot a_{p}^{0.75} \leq F_{\max }
$$

where $F_{\max }$ is the maximal allowable cutting force.

The surface quality of turned parts is one of the most frequent customer requirements. In finishing operations, it must not be greater than the maximal specified value $\left(R_{\text {amax }}\right)$. The surface roughness constraint, in terms of main turning parameters, can be expressed as:

$$
14785 \cdot v^{-1.52} \cdot f^{1.004} \cdot a_{p}^{0.25} \leq R_{a_{\max }}
$$

The other necessary cutting data for formulation and solving of the considered turning optimization problem, as proposed by Agapiuou [3], are given in Table 1.

\begin{tabular}{|c|c|c|c|}
\hline Parameter & Value & Parameter & Value \\
\hline$L$ & $203 \mathrm{~mm}$ & $P_{\max }$ & $5 \mathrm{~kW}$ \\
\hline$D$ & $152 \mathrm{~mm}$ & $\theta_{\max }$ & $500{ }^{\circ} \mathrm{C}$ \\
\hline$v_{\min }$ & $30 \mathrm{~m} / \mathrm{min}$ & $F_{\max }$ & $900 \mathrm{~N}$ \\
\hline$v_{\max }$ & $200 \mathrm{~m} / \mathrm{min}$ & $a_{I}$ & 0.29 \\
\hline$f_{\min }$ & $0.254 \mathrm{~mm} / \mathrm{rev}$ & $a_{2}$ & 0.35 \\
\hline$f_{\max }$ & $0.762 \mathrm{~mm} / \mathrm{rev}$ & $a_{3}$ & 0.25 \\
\hline$a_{p \min }$ & $2 \mathrm{~mm}$ & $t_{h}$ & $1.5 \mathrm{~min}$ \\
\hline$a_{p \max }$ & $5 \mathrm{~mm}$ & $t_{R}$ & $0.13 \mathrm{~min}$ \\
\hline$R_{\text {amax }}$ & $20 \mu \mathrm{m}$ & $t_{c s}$ & $0.5 \mathrm{~min}$ \\
\hline
\end{tabular}

Table 1. Optimization model data

After setting the values from Table 1 and normalizing constraints, the final formulation of the considered turning optimization problem is reduced to:

Minimize: $T_{u}=\frac{30.856 \cdot \pi}{v \cdot f}+\frac{\frac{15.428 \cdot \pi}{v \cdot f}}{\left(\frac{193.3}{v \cdot f^{0.29} \cdot a_{p}^{0.35}}\right)^{4}}+1.63$

Subject to: $g_{1}=0.0373 \cdot v^{0.91} \cdot f^{0.78} \cdot a_{p}^{0.75} \leq 5$

$$
\begin{aligned}
& g_{2}=14785 \cdot v^{-1.52} \cdot f^{1.004} \cdot a_{p}^{0.25} \leq 20 \\
& g_{3}=74.96 \cdot v^{0.4} \cdot f^{0.2} \cdot a_{p}^{0.105} \leq 500 \\
& g_{4}=844 \cdot v^{-0.1013} \cdot f^{0.725} \cdot a_{p}^{0.75} \leq 900
\end{aligned}
$$

The final turning optimization problem, as formulated in Equation 9, is the constrained nonlinear optimization problem with three continuous independent variables.

\section{RESULTS AND DISCUSSION}

For solving the above given turning optimization problem exhaustive iterative search algorithm, provided in the specialized software tool "BRUTOMIZER" [20] was used.

The iterative search algorithm was selected as it represents a parameter free optimization approach that only requires performing a large number of computations that are, however, executed very fast. Moreover, one can take into account technotechnological possibilities of available machine tools in terms of setting particular permissible values for main turning parameter values. The optimization process was run on Intel Core2Duo T5800 with 4 GB RAM.

Table 2 shows the determined optimization values for cutting speed, feed rate, depth of cut and corresponding total production times.

For the purpose of optimization solutions comparison, another set of optimization solutions was determined (Table 3), given that maximal temperature of tool workpiece interface is set to $\theta_{\max }=550{ }^{\circ} \mathrm{C}$ in constraint $\mathrm{g}_{3}$ (Equation 6). Namely, Chauhan et al. [11] applied LXPM and DE for solving this optimization problem with modified constraint $g_{3}$.

As could be observed from Table 2, determination of optimal values of cutting speed, depth of cut and feed rate is predominantly conditioned by the maximal temperature of tool workpiece interface constraint $\left(\mathrm{g}_{3}\right)$. In the case of solving the optimization problem with modified constraint $\mathrm{g}_{3}$, i.e. when maximal temperature of tool workpiece interface is set to $\theta_{\max }=550{ }^{\circ} \mathrm{C}$, the most critical constraint to be satisfied is related to maximal allowable machine tool power $\left(\mathrm{g}_{1}\right)$.

The optimization solutions obtained using different meta-heuristic algorithms applied by previous researchers are summarized in Tables 4-6.

As could be observed from Tables 4-6, on a first sight the use of different meta-heuristic algorithms provided a set of better optimization solutions for the considered turning optimization problem with constraints. However, after a careful analysis of the given optimization solutions and checking the given constraints as given by Equations 5-8 it turned out that many determined optimization solutions are feasible because of constraints violations. The summary is given in Table 7.

As could be observed from Table 7 , it turned out that only $\mathrm{DE}$ managed to correctly handle given constraints, while the other meta-heuristic algorithms such as GA, SA, LXPM and PSO were not able to determine feasible solutions which satisfy all proposed conditions. 


\begin{tabular}{|c|c|c|c|c|c|c|c|c|}
\hline Solution & $a_{p}(\mathrm{~mm})$ & $v(\mathrm{~m} / \mathrm{min})$ & $f(\mathrm{~mm} / \mathrm{rev})$ & $T_{u}(\mathrm{~min})$ & $g_{I}$ & $g_{2}$ & $g_{3}$ & $g_{4}$ \\
\hline 1 & 2 & 109.73 & 0.762 & 2.90458 & 3.648 & 10.6 & 499.987 & 724.181 \\
\hline 2 & 2.5 & 104.04 & 0.754 & 2.99979 & 4.075 & 12.024 & 499.99 & 854.179 \\
\hline 3 & 3 & 105.68 & 0.664 & 3.18929 & 4.292 & 10.816 & 499.986 & 891.712 \\
\hline 4 & 3.5 & 109.16 & 0.574 & 3.41487 & 4.429 & 9.245 & 499.994 & 897.736 \\
\hline 5 & 4 & 113.61 & 0.494 & 3.67288 & 4.516 & 7.737 & 499.986 & 886.392 \\
\hline 6 & 4.5 & 116.19 & 0.444 & 3.90064 & 4.633 & 6.918 & 499.989 & 894.134 \\
\hline 7 & 5 & 119.98 & 0.394 & 4.17102 & 4.703 & 6 & 499.993 & 884.486 \\
\hline
\end{tabular}

Table 2. The production time and corresponding turning parameter values

\begin{tabular}{|c|c|c|c|c|c|c|c|c|}
\hline Solution & $a_{p}(\mathrm{~mm})$ & $v(\mathrm{~m} / \mathrm{min})$ & $f(\mathrm{~mm} / \mathrm{rev})$ & $T_{u}(\mathrm{~min})$ & $g_{1}$ & $g_{2}$ & $g_{3}$ & $g_{4}$ \\
\hline 1 & 2 & 139.26 & 0.762 & 2.779 & 4.531 & 7.378 & 549.995 & 706.907 \\
\hline 2 & 2.5 & 129.07 & 0.762 & 2.872 & 4.999 & 8.756 & 546.178 & 842.147 \\
\hline 3 & 3 & 121.68 & 0.685 & 3.066 & 4.999 & 9.007 & 532.295 & 899.138 \\
\hline 4 & 3.5 & 122.69 & 0.585 & 3.319 & 4.999 & 7.889 & 525.91 & 899.466 \\
\hline 5 & 4 & 123.62 & 0.51 & 3.576 & 4.999 & 7.027 & 520.469 & 899.388 \\
\hline 6 & 4.5 & 124.41 & 0.452 & 3.836 & 4.999 & 6.348 & 515.687 & 899.535 \\
\hline 7 & 5 & 125.32 & 0.405 & 4.101 & 4.999 & 5.773 & 511.588 & 898.349 \\
\hline
\end{tabular}

Table 3. Optimization solutions obtained under modified constraint $g_{3}$

\begin{tabular}{|c|c|c|c|c|c|c|c|c|}
\hline \multirow{2}{*}{ Solution } & \multicolumn{4}{|c|}{ GA } & \multicolumn{4}{c|}{ SA } \\
\cline { 2 - 9 } & $\begin{array}{c}a_{p} \\
(\mathrm{~mm})\end{array}$ & $\begin{array}{c}v \\
(\mathrm{~m} / \mathrm{min})\end{array}$ & $\begin{array}{c}f \\
(\mathrm{~mm} / \mathrm{rev})\end{array}$ & $\begin{array}{c}T_{u} \\
(\mathrm{~min})\end{array}$ & $\begin{array}{c}a_{p} \\
(\mathrm{~mm})\end{array}$ & $\begin{array}{c}v \\
(\mathrm{~m} / \mathrm{min})\end{array}$ & $\begin{array}{c}f \\
(\mathrm{~mm} / \mathrm{rev})\end{array}$ & $\begin{array}{c}T_{u} \\
(\mathrm{~min})\end{array}$ \\
\hline 1 & 2 & 118.91 & 0.764 & 2.85 & 2 & 120.39 & 0.753 & 2.85 \\
\hline 2 & 2.5 & 114.15 & 0.644 & 3.12 & 2.5 & 112.57 & 0.761 & 2.93 \\
\hline 3 & 3 & 114.49 & 0.665 & 3.13 & 3 & 116.68 & 0.648 & 3.15 \\
\hline 4 & 3.5 & 120.61 & 0.531 & 3.46 & 3.5 & 118.21 & 0.582 & 3.34 \\
\hline 5 & 4 & 106.16 & 0.565 & 3.51 & 4 & 122.05 & 0.507 & 3.59 \\
\hline 6 & 4.5 & 104.8 & 0.454 & 3.96 & 4.5 & 125.41 & 0.448 & 3.85 \\
\hline 7 & 5 & 110.58 & 0.435 & 4.14 & 5 & 126.28 & 0.4 & 4.12 \\
\hline
\end{tabular}

Table 4. The production time and corresponding turning parameter values given by Saravanan et al. [5]

\begin{tabular}{|c|c|c|c|c|}
\hline \multirow{2}{*}{ Solution } & \multicolumn{4}{|c|}{ PSO } \\
\cline { 2 - 5 } & $\begin{array}{c}a_{p} \\
(\mathrm{~mm})\end{array}$ & $\begin{array}{c}v \\
(\mathrm{~m} / \mathrm{min})\end{array}$ & $\begin{array}{c}f \\
(\mathrm{~mm} / \mathrm{rev})\end{array}$ & $\begin{array}{c}T_{u} \\
(\mathrm{~min})\end{array}$ \\
\hline 1 & 2 & 139.9 & 0.762 & 2.78 \\
\hline 2 & 2.5 & 131.94 & 0.762 & 2.87 \\
\hline 3 & 3 & 131.73 & 0.695 & 3.04 \\
\hline 4 & 3.5 & 134.98 & 0.594 & 3.29 \\
\hline 5 & 4 & 134.54 & 0.517 & 3.55 \\
\hline 6 & 4.5 & 133.78 & 0.458 & 3.82 \\
\hline 7 & 5 & 132.15 & 0.41 & 4.08 \\
\hline
\end{tabular}

Table 5. The production time and corresponding turning parameter values given by Deep and Bansal [21]

\begin{tabular}{|c|c|c|c|c|c|c|c|c|c|}
\hline \multirow{3}{*}{ Solution } & \multicolumn{4}{|c|}{ LXPM } & \multicolumn{4}{|c|}{ DE } & \\
\cline { 2 - 8 } & $\begin{array}{c}a_{p} \\
(\mathrm{~mm})\end{array}$ & $\begin{array}{c}v \\
(\mathrm{~m} / \mathrm{min})\end{array}$ & $\begin{array}{c}f \\
(\mathrm{~mm} / \mathrm{rev})\end{array}$ & $\begin{array}{c}T_{u} \\
(\mathrm{~min})\end{array}$ & $\begin{array}{c}a_{p} \\
(\mathrm{~mm})\end{array}$ & $\begin{array}{c}v \\
(\mathrm{~m} / \mathrm{min})\end{array}$ & $\begin{array}{c}f \\
(\mathrm{~mm} / \mathrm{rev})\end{array}$ & $\begin{array}{c}T_{u} \\
(\mathrm{~min})\end{array}$ \\
\hline 1 & 2 & 139.26 & 0.762 & 2.78 & 2 & 139.26 & 0.761 & $2.78^{*}$ \\
\hline 2 & 2.5 & 129.07 & 0.762 & 2.87 & 2.5 & 129.07 & 0.761 & 2.87 \\
\hline 3 & 3 & 122.72 & 0.686 & 3.06 & 3 & 121.56 & 0.685 & 3.06 & Corrected \\
& values \\
\hline 4 & 3.5 & 122.43 & 0.585 & $3.32^{*}$ & 3.5 & 122.61 & 0.585 & $3.32^{*}$ \\
\hline 5 & 4 & 134.54 & 0.517 & 3.55 & 4 & 123.53 & 0.51 & 3.57 \\
\hline 6 & 4.5 & 127.92 & 0.454 & 3.82 & 4.5 & 124.34 & 0.452 & $3.84^{*}$ \\
\hline 7 & 5 & 132.15 & 0.41 & 4.07 & 5 & 125.08 & 0.405 & $4.1^{*}$ & \\
\hline
\end{tabular}

Table 6. Optimization solutions as given by Chauhan et al. [11] (modified constraint $\mathrm{g}_{3}$ )

\begin{tabular}{|c|c|c|c|c|c|}
\hline \multirow{2}{*}{ Solution } & \multicolumn{5}{|c|}{ Meta-heuristic algorithm } \\
\cline { 2 - 6 } & GA & SA & LXPM & DE & PSO \\
\hline 1 & $\mathrm{~g}_{3}(516.587)$ & $\mathrm{g}_{3}(517.663)$ & $\mathrm{OK}$ & $\mathrm{OK}$ & $\mathrm{g}_{3}(551.005)$ \\
\hline 2 & $\mathrm{~g}_{3}(502.783)$ & $\mathrm{g}_{3}(516.962)$ & $\mathrm{OK}$ & $\mathrm{OK}$ & $\mathrm{g}_{3}(551.004)$ \\
\hline 3 & $\mathrm{~g}_{3}(516.414)$ & $\mathrm{g}_{3}(517.665)$ & $\mathrm{g}_{1}(5.044)$ & $\mathrm{OK}$ & $\mathrm{g}_{3}(551.059)$ \\
\hline 4 & $\mathrm{~g}_{3}(512.305)$ & $\mathrm{g}_{3}(517.61)$ & $\mathrm{OK}$ & $\mathrm{OK}$ & $\mathrm{g}_{3}(548.052)$ \\
\hline 5 & $\mathrm{~g}_{4}(983.768)$ & $\mathrm{g}_{3}(517.222)$ & $\mathrm{g}_{1}(5.458)$ & $\mathrm{OK}$ & $\mathrm{g}_{3}(539.864)$ \\
\hline 6 & $\mathrm{~g}_{4}(918.237)$ & $\mathrm{g}_{3}(516.423)$ & $\mathrm{g}_{1}(5.145)$ & $\mathrm{OK}$ & $\mathrm{g}_{3}(532.287)$ \\
\hline 7 & $\mathrm{~g}_{4}(958.178)$ & $\mathrm{g}_{3}(511.878)$ & $\mathrm{g}_{1}(5.298)$ & OK & $\mathrm{g}_{3}(523.847)$ \\
\hline
\end{tabular}

Table 7. Analysis of constraints violations in the determined optimization solutions by meta-heuristic algorithms 
Namely, the most common method for handling linear, non-linear, equality or inequality constraints in the application of meta-heuristic algorithms is the use of penalty functions, i.e. transformation of a constrained to an unconstrained optimization problem. However, as noted by Chehouri et al. [22], the use of penalty functions necessities the definition and proper tuning of specific metaheuristic algorithm parameters, which can be challenging and problematic.

From the analysis of determined optimization results, as well as after checking constraints violations, it is clear that the proposed optimization approach provided the best optimization solutions. As could be observed from the obtained optimization results, the metaheuristic algorithms, i.e. LXPM provided the same optimization results in the case of solution 1 and solution 2 for the modified optimization problem. Thus, one can argue that the proposed optimization approach yielded better optimization results while solving complex turning optimization problem with several nonlinear constraints. Finally, for each depth of cut, the minimal determined production times are given in Figure 1.

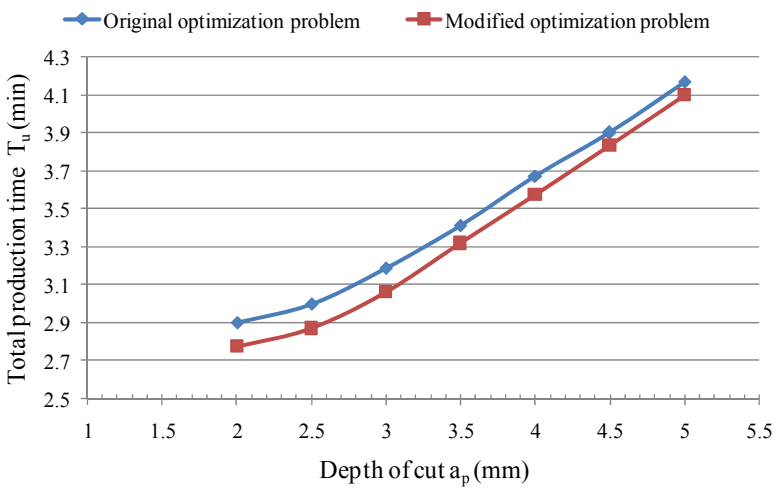

Fig. 1. The set of minimal permissible total production times for different depth of cuts obtained with the proposed optimization approach

From Figure 1 one can observe that in the case when maximal temperature of tool workpiece interface constraint is relaxed one reduces the total production time since higher cutting speeds are allowed. It could be also observed that with an increase in the depth of cut, there is an almost linear increase in the total production time. Although this may seem unusual, one should consider paired values for cutting speed, and especially feed rate, as well as the inevitability to satisfy the set nonlinear constraints.

\section{CONCLUSION}

So far a number of optimization approaches and methods were applied for solving complex turning optimization problems with constraints. This paper proposed the use of conceptually simple and parameter free optimization approach based on the use of exhaustive iterative search. The optimization model of minimization of production time in single-pass turning process was considered for demonstration of the applicability and suitability of the optimization approach as well as to compare the optimization results with those previously obtained with the use of metaheuristic algorithms. From the obtained optimization results it can be concluded that the solutions previously determined by past researchers using meta-heuristic algorithms were improved. It has been observed that the presented approach is able to provide reliable and feasible optimization solutions within a reasonable computational time. Optimization solutions obtained in this way can be recorded in the $\mathrm{CAD} / \mathrm{CAM}$ database for automatic generation of $\mathrm{CNC}$ code. On the other hand, after careful and comprehensive analysis of the optimization solution obtained with the use of metaheuristic algorithms, it turned out that a number of obtained solutions were not feasible because of constraints violation pointing out the necessity of fine tuning of meta-heuristic algorithm parameters so as to be able to handle appropriately nonlinear constraints.

Since turning optimization problems may consider non-smooth and non-convex objective functions in terms of decision variables of continous and discrete type as well as different non-linear and linear contraints of equality and inequality type, the proposed optimization approach seems justified. Moreover, it can be easily extended for solving multi-objective constrained turning optimization problems, as well as other conventional and non-conventional machining processes such as milling, grinding, abrasive waterjet machining etc. and this is the future research scope.

\section{REFERENCES}

[1] Armarego, E.J.A., Brown, R.H.: The machining of metals, Prentice Hall, 1969.

[2] Sundaram, R.M.: An application of goal programming technique in metal cutting, International Journalof Production Research, Vol. 16, No. 5, p.p. 375-382, 1978.

[3] Agapiou, J.S.: The optimization of machining operations basedon a combined criterion, Part 1: the use of combined objectivesin single pass operations, Transactions ASME, Journal of Engineering for Industry, Vol. 114, No. 4, p.p. 500507,1992

[4] Mesquita, R., Krasteva, E., Doytchinov, S.: Computer-aided selection of optimum machining parameters in multi-pass turning, International Journal of Advanced Manufacturing Technology, Vol. 10, No. 1, p.p. 19-26, 1995.

[5] Saravanan, R., Asokan, P., Sachithanandam, M.: Comparative analysis of conventional and nonconventional optimisation techniques for CNC turning process, The International Journal of Advanced Manufacturing Technology, Vol. 17, No. 7, p.p. 471-476, 2001

[6] Saravanan, R., Sankar, R.S., Asokan, P., Vijayakumar, K., Prabhaharan, G.: Optimization of cutting conditions during continuous finished profile machining using non-traditional techniques, The International Journal of Advanced Manufacturing Technology, Vol. 26, No. 1, p.p. 3040, 2005. 
[7] Vijayakumar, K., Prabhaharan, G., Asokan, P., Saravanan, R.: Optimization of multi-pass turning operations using ant colony system, International Journal of Machine Tools and Manufacture, Vol. 43, No. 15, p.p. 1633-1639, 2003.

[8] Ameur, T., Assas, M.: Modified PSO algorithm for multi-objective optimization of the cutting parameters, Production Engineering, Vol. 6, No. 6, p.p. 569-576, 2012.

[9] Raja, S.B., Narayanan, N.S., Pramod, C.S., Ragunathan, A., Vinesh, S.R., Krishna, K.V.: Optimization of constrained machining parameters in turning operation using firefly algorithm, Journal of Applied Sciences, Vol. 12, No. 10, p.p. 10381042, 2012.

[10] Belloufi, A., Assas, M., Rezgui, I.: Intelligent selection of machining parameters in multipass turnings using firefly algorithm, Modelling and Simulation in Engineering, Vol. 1, No. 1, p.p. 1-8, 2014.

[11] Chauhan, P., Deep, K., Pant, M.: Optimizing CNC turning process using real coded genetic algorithm and differential evolution, Transaction on Evolutionary Algorithm and Continuous Optimization, Vol 2, No. 2, p.p. 157-165, 2011.

[12] Chauhan, P., Pant, M., Deep, K.: Parameter optimization of multi-pass turning using chaotic PSO, International Journal of Machine Learning and Cybernetics, Vol. 6, No. 2, p.p. 319-337, 2015.

[13] Mellal, M.A., Williams, E.J.: Cuckoo optimization algorithm for unit production cost in multi-pass turning operations, The International Journal of Advanced Manufacturing Technology, Vol. 76, No. 1-4, p.p. 647-656, 2015.

[14] Satishkumar, S., Asokan, P., Kumanan, S.: Optimization of depth of cut in multi-pass turning using nontraditional optimization techniques, The International Journal of Advanced Manufacturing Technology, Vol. 29, No. 3-4, p.p. 230-238, 2006.

[15] Shin, Y.C., Joo, Y.S.: Optimization of machining condition with practical constraints, International Journal of Production Research, Vol. 30, No. 12, p.p. 2907-2919, 1992.

[16] Srinivas, J., Giri, R., Yang, S.H.: Optimization of multi-pass turning using particle swarm intelligence, The International Journal of Advanced Manufacturing Technology, Vol. 40, No. 1, p.p. 5666, 2009.

[17] Chen, M.-C., Tsai, D.-M.: A simulated annealing approach foroptimization of multi-pass turning operations, International Journal of Production Research, Vol. 34, No. 10, p.p. 2803-2825, 1996.

[18] Yildiz, A.R.: Optimization of multi-pass turning operations using hybrid teaching learning-based approach, The International Journal of Advanced Manufacturing Technology, Vol. 66, No. 9-12, p.p. 1319-1326, 2013.

[19] Xu, S., Wang, Y., Huang, F.: Optimization of multipass turning parameters through an improved flower pollination algorithm, The International Journal of Advanced Manufacturing Technology, Vol. 89, No. 1-4, p.p. 503-514, 2017.

[20] http://www.virtuode.com/?page=SoftwareSolution
[21] Deep, K., Bansal, J.C.: Performanse analysis of turning process via particle swarm optimization, Studies in Computational Intelligence, Vol. 129, No. 1, p.p. 453-460, 2008.

[22] Chehouri, A., Younes, R., Perron, J., Ilinca, A.: A constraint-handling technique for genetic algorithms using a violation factor, Journal of Computer Science, Vol. 12, No. 7, p.p. 350-362, 2016.

Authors: ${ }^{1}$ Assist. Miloš Madić PhD, ${ }^{1}$ Professor Miroslav Radovanović PhD, ${ }^{2}$ MSc Marko Kovačević ${ }^{1}$ University of Niš, Faculty of Mechanical Engineering in Niš, Aleksandra Medvedeva 14, 18000 Niš, Serbia, Phone: +381 18 500-687, Fax: +381 18 588-244;

${ }^{2}$ University of Niš, Faculty of Electronic Engineering Engineering in Niš, Aleksandra Medvedeva 14, 18000 Niš, Serbia.

E-mail: madic@masfak.ni.ac.rs mirado@masfak.ni.ac.rs marko.kovacevic@elfak.ni.ac.rs 